\title{
Testing the reproductive benefits of aggregation: the limpet Patella vulgata shows no evidence of synchrony in gonad development
}

\author{
Ross A. Coleman ${ }^{1,3, *}$, Stephen J. Hawkins ${ }^{2}$, Hannah L. Wood ${ }^{1}$ \\ ${ }^{1}$ Marine Biology \& Ecology Research Centre, School of Biological Sciences, University of Plymouth, Drake Circus, \\ Plymouth PL4 8AA, UK \\ ${ }^{2}$ The Marine Biological Association, The Laboratory, Citadel Hill, Plymouth PL1 2PB, UK \\ ${ }^{3}$ Present address: Centre for Research on Ecological Impacts of Coastal Cities, Marine Ecology Laboratories (A11), \\ The University of Sydney, New South Wales 2006, Australia
}

\begin{abstract}
Group living is ubiquitous, yet causal explanations are not fully tested. Evidence for a reduction in predation risk is clear, and there is support for reduction of risk from the abiotic environment. Potential reproductive benefits are less well understood, especially for non-lekking, externally fertilising animals which form medium-term aggregations. We used Patella vulgata to test the model that a reproductive benefit is derived from aggregation. We sampled grouped and solitary limpets fortnightly, from the point at which individuals were in a neuter state to the stage where the population was near spawning. Whilst aggregation increased overall as the population neared spawning, there was no difference between aggregated and solitary limpets in terms of sex ratio. There was also no difference in variability of gonad development between solitary and grouped animals, which means no synchrony in gonad development was necessary for externally fertilising animals to gain a benefit from aggregating. We suggest that causal explanations for an increase in limpet aggregation from autumn to winter are most likely to lie in the interaction of reduced grazing activity and increased predation pressure. Since limpets are a key component of rocky shore systems, understanding the processes determining their spatial arrangement has implications for our understanding of rocky shores.
\end{abstract}

KEY WORDS: Aggregation $\cdot$ Patella vulgata $\cdot$ Grazing $\cdot$ Behaviour $\cdot$ Reproduction

\section{INTRODUCTION}

Aggregation by animals is a phenomenon frequently observed but not fully explained; thus, the reasons for group living have long been the subject of debate (see Krause \& Ruxton 2002 for review). Reduction in predation risk has been the focus of most attention (e.g. Hamilton 1971, Kenward 1978, Parrish \& Edelstein-Keshet 1999, Coleman et al. 2004a). Grouping may also reduce risk from the physical stresses, i.e. temperature (Feare 1971) or damage from mobile objects (Shanks \& Wright 1986). Another possible advantage is access to potential mates or successful fertilisation opportunities; this is particularly important in sessile cross-fertilising hermaphrodites (e.g. barnacles, Anderson 1994) or animals utilising external fertilisation, which predominate in marine systems. The reproductive advantages of aggregation and synchronised spawning have been well covered for some mobile taxa (Pennington 1985, Levitan et al. 1991) and for sessile organisms such as barnacles (Anderson 1994, Kent et al. 2003). It has been suggested that animals which form medium term aggregations such as Patella vulgata (Coleman \& Hawkins 2000) may gain some reproductive benefit from aggregating (Coleman et al. 1999, Powell et al. 2001, Krause \& Ruxton 2002), but this model has not been formally tested. 
The majority of marine invertebrates reproduce by external fertilisation, the most common form of which is broadcast spawning; individuals release gametes into the water column where fertilisation then takes place. Gamete dilution is the main limiting factor in external fertilisation (Metaxas et al. 2002) because the probability of success decreases with increased gamete dispersal (Levitan 1996). The continued persistence of external fertilisation as a sexual strategy in a large number of marine species implies that adaptations have been selected to enhance fertilisation success, including synchronised spawning and aggregation (Levitan \& Petersen 1995, Levitan 2002). Aggregation combined with synchronisation of spawning may increase fertilisation rate as the mass release of gametes creates a localised area of high sperm and egg concentration, thus giving a higher probability of a sperm and egg collision (Denny \& Shibata 1989, Levitan 2002). The reproductive biology of Patella vulgata L., a broadcast spawner, has been extensively studied (e.g. Orton et al. 1956, Thompson 1980), and loose synchrony in gonad development has been noted at a population level, independent of biotic interactions (Orton et al. 1956). There has been little or no work specifically designed to investigate behavioural adaptations which may lead to enhanced fertilisation.

Limpets of the genus Patella are fundamental to ecosystem processes on the mid-shore regions of exposed and moderately exposed rocky shores in the Northeast Atlantic (Jones 1946, Southward \& Southward 1978, Hawkins \& Hartnoll 1983); elsewhere, grazing by limpets has also been shown to be key in controlling macroalgal abundance (Hawkins et al. 1992, Underwood 2000, Dunmore \& Schiel 2003). Patella spp. can occur distributed randomly and in groups of different sizes and degrees of aggregation, on bare rock and under clumps of macroalgae (Jones 1948, Lewis \& Bowman 1975, Hartnoll \& Hawkins 1985, Coleman et al. 1999). Whilst some patellid limpets are known to show a degree of fidelity to their home-scars (see Branch 1985 for review), relocations by individuals have been noted (Coleman \& Hawkins 2000). Grouping by limpets seems to vary with season, being maximal in winter and decreasing in spring in the UK (Coleman et al. 1999) and in Portugal (Boaventura et al. 2002). These greater levels of aggregation in winter could be a response to elevated wave action or may increase the chances of successful fertilisation by reducing distances between spawning individuals. Smaller limpets are likely to be male, as $P$. vulgata are sequential hermaphrodites. Previous work has shown that there was no difference in average size or in size variation between limpet groups and solitary limpets (Coleman et al. 1999).

Patella vulgata is a winter spawning species with gonad maturation starting around August, following an extended resting period (6 mo) during which all individuals are considered neuter. Over approximately $4 \mathrm{mo}$, the gonads develop. The stage of gonad maturity can be scored using a scale of 1 to 5 , where 5 is a fully developed gonad with mature gametes ready for shedding (Orton et al. 1956). Spawning takes place between November and January in 1 or 2 spawning events (Blackmore 1969), possibly triggered by rough seas (Orton et al. 1956), before the limpets pass into the resting phase, with a decline in gonad size back to that of the neuter resting phase.

Here, we evaluate whether aggregation by limpets may improve their individual potential reproductive output. We would expect aggregation to increase near the time of spawning if aggregation increases the likelihood of fertilisation. Since free-spawning organisms are usually sperm limited (Denny \& Shibata 1989, Metaxas et al. 2002), we predicted that if aggregation promoted synchronous spawning, there would be less sperm limitation at a small spatial scale (i.e. that of groups). Therefore, the sex ratio in groups would be less male biased than in populations of singletons. We also hypothesised that, whilst the frequency of limpets in each stage of gonad development would not differ between limpets living as singletons and those in groups, the variation in gonad stage between individuals should be less, i.e. more synchronous, for grouped limpets than for solitary ones.

\section{MATERIALS AND METHODS}

Experimental sites and specimen collection. All data were collected from 2 moderately exposed rocky shores in the southwest of the UK: Wembury $\left(50^{\circ}\right.$ $\left.19.00^{\prime} \mathrm{N}, 04^{\circ} 05.98^{\prime} \mathrm{W}\right)$ and Heybrook Bay (50 $19.18^{\prime} \mathrm{N}$, $04^{\circ} 07.27^{\prime} \mathrm{W}$ ), chosen as representative of shores in the region. The intertidal zone at each shore is dominated by barnacles and patellid limpets with patchy fucoid cover. Since barnacles compete with limpets for space (Johnson et al. 1997), and fucoid cover has been reported to affect aggregation (Hartnoll \& Hawkins 1985), 2 mid-shore sites $\left(\sim 10 \mathrm{~m}^{2}\right)$ of predominantly smooth flat rock with few barnacles and no fucoids were selected at each shore; each site was more than $10 \mathrm{~m}$ from the other. As topography has been described as influencing limpet aggregation (Hawkins 1981), to ensure that sites were consistent, tests for variation in topography (surface heterogeneity) were carried out prior to sampling. Surface heterogeneity was tested by using 10 random quadrats $(0.25 \times 0.25 \mathrm{~m})$. A $5 \mathrm{~mm}$ link chain was laid over the substratum across the diagonal of each quadrat; the chain was in contact with the substratum at every point. The difference between the actual length of this chain and the length of the chain when it was pulled taut across the diagonal of the quadrat, which was then averaged across 
both diagonals, gave a measure of the surface heterogeneity at that quadrat. Differences between sites and shores were tested for using ANOVA, run on WinGMAV (EICC, University of Sydney). Cochran's test was used to test heterogeneity of variance (Underwood 1997), and comparisons of levels within significant factors were made by Student-Newman-Keuls (SNK) tests.

Patella vulgata were collected fortnightly on every spring tide from late August 2003 through to the end of December 2003 (9 sampling occasions). On each occasion at each site, 5 limpets were collected from each of 5 randomly chosen groups ( 25 in total); in addition, 25 solitary limpets were collected. Each group of limpets contained at least 5 individuals and occupied an area of approximately $0.4 \times 0.4 \mathrm{~m}$ (Coleman et al. 1999). To avoid possible confounding with different reproductive development cycles (Ballantine 1961), limpets in mixed species clusters or near an individual of another species (P. aspera or P. depressa) were not used. All limpets collected were between 30 and $40 \mathrm{~mm}$ (anterior-posterior axis); bias towards either small or large size was avoided as $P$. vulgata are sequential hermaphrodites (Orton et al. 1956) and a size bias might have led to a sex bias within the samples. In the range 20 to $30 \mathrm{~mm}, 90 \%$ of limpets are male, whereas limpets larger than $40 \mathrm{~mm}$ are mostly female (Orton et al. 1956); limpets on the shores investigated can reach up to $55 \mathrm{~mm}$ (R. A. Coleman unpubl. data). Previous work had shown that groups were extremely rarely composed of individuals of identical size (R. A. Coleman, J. G. Goss-Custard \& S. J. Hawkins unpubl. data). Gonad development and sex were established either immediately on return to the laboratory, or following overnight storage at $4^{\circ} \mathrm{C}$.

Patterns of aggregation. Pielou's $\mathrm{I}_{\alpha}$ (Pielou 1969) was used as a scale-independent index of aggregation (Coleman et al. 1999, 2004b) from random point to nearest limpet data. These data were collected from 10 random $0.5 \times 0.5 \mathrm{~m}$ quadrats at each site, every third spring tide cycle from September (the start of gonad development, Orton et al. 1956) to December (near the time of spawning). Three replicate measures of $I_{\alpha}$ were collected from each quadrat; each quadrat location was unique to the sampling occasion. Differences in aggregation between shores, sites or quadrats and the effect of date were analysed using ANOVA as above, with date and aggregation as fixed factors; all other factors were random. It was possible that the fortnightly removal of limpets throughout the study could affect aggregation at the study sites. Therefore, aggregation data from both Wembury sites on the final date (the aggregation index taken after the greatest cumulative Patella vulgata removal) were compared to aggregation data from 2 similar random sites on the same shore, but where no limpets had been removed. Data were tested for differences in aggregation using ANOVA as before.
Gonad development in aggregated and solitary limpets. Limpets show no secondary sexual characteristics, so observations of sex and reproductive stage were made directly on the gonad. The posterior end of the foot was cut away from the visceral mass and turned back to reveal the gonad. The sex and gonad state of each specimen were then recorded using the scheme described by Orton et al. (1956). For animals which showed gonad development, we examined the proportion of male animals in each quadrat. These data were arcsin-transformed and analysed using ANOVA. To test the hypothesis that limpets in groups would have a different frequency of individuals at each gonad stage, we used a log-linear analysis (Sokal \& Rohlf 1995) run on SPSS software using a backward elimination approach. To avoid generation of too many zero cells, we allocated each gonad stage to 1 of 3 exclusive classes: neuter, developing (Orton et al.'s I to III) or fully developed/emptying (Orton et al.'s IV and V). Significant factors were then examined using $\chi^{2}$ contingency tests.

Synchronicity in gonad development would be manifested by low variance between individuals. To test whether gonad development was more variable in grouped limpets or between solitary limpets, we used a meta-analysis approach (Osenberg et al. 1999). Each group of 5 limpets was randomly paired with a set of 5 solitary limpets in each site on each shore for each date. The response ratio $\ln (g) / \ln (s)$ (Hedges et al. 1999) was then calculated, where $g$ is the variance in gonad stage for the grouped limpets and $s$ that for solitary limpets. If the response ratio is larger than zero, then variation in gonad stage is greater in grouped limpets than in solitary, and vice versa for a negative response ratio. This provided a measure of effect size (Hedges et al. 1999) at each site and shore for each date. These response-ratios were analysed by ANOVA. A difference from an expected mean of zero was tested by a Student's $t$-test.

\section{RESULTS}

\section{Site comparability for experimental sites}

Analysis of variance for shore topography showed no significant difference in surface heterogeneity between shores $\left(F_{1,2}=0.28\right.$, not significant (ns)), or between sites within shores $\left(F_{2,36}=1.93, \mathrm{~ns}\right)$, the average difference in chain length was $8.99 \mathrm{~mm}(\mathrm{n}=40, \mathrm{SE}=0.52)$. All sites were at a similar tidal height of $1.8 \mathrm{~m}$ above chart datum.

\section{Patterns of aggregation}

Data were $\ln (x+1)$ transformed to stabilise variances; the ANOVA (Table 1) showed a significant small-scale 
effect, that of quadrats being very different for each time/site/shore combination. The effect is largely due to a decrease in maximal aggregation from the September to the October sample, then a substantial increase in aggregation at the last sample, with many quadrats having a very high maximal value (Fig. 1). Thus, whilst there was much variation at the quadrat scale, and between sites within the 2 shores used, overall aggregation did markedly increase from the second to the third sample. Removal of limpets for sampling purposes did not appear to significantly affect the patterns of aggregation $\left(F_{1,2}=3.82\right.$, ns mean aggregation on removal sites $\mathrm{I}_{\alpha}=1.75, \mathrm{SE}=0.5$; mean aggregation on non-removal sites $\mathrm{I}_{\alpha}=1.43, \mathrm{SE}=0.20 ; \mathrm{n}=60$ for both).

\section{Gonad development in aggregated and solitary limpets}

Since, in the August sample, many individuals were neuter, the first sampling date was not included in the sex ratio analysis. The ratio of males to females did vary, but the only significant factor was date (Table 2); SNK tests could not separate dates. On average, most animals in the size range sampled were in a male phase ( 70 to $80 \%$, Fig. 2 ).

Level of aggregation (solitary or grouped) did not contribute to variation in gonad stage over time; this was best explained by an interaction of date and site $\left(\chi^{2}\right.$ change $=100.81$, df $=$ $48, \mathrm{p}<0.001)$. Contingency tests on this interaction showed that sites were significantly different only at the first sample in August $\left(\chi^{2}=17.52\right.$, df $\left.=8, p<0.05\right)$; the development of gonads was only really explained by time (Fig. 3). Late in the sampling period (December), a few animals showed evidence of spawning.

For the analysis of response ratios of variance in gonad development, the test for Date $\times$ Shore and Date $\times$ Site(Shore) gave a probability of $>0.25$ and the mean square was less than the residual, so these factors were eliminated from the analysis. This increased the power of tests for main effects (Underwood 1997). There was no significant variation in the response ratio that could be explained by the date at which the sample was obtained or by shore or site (Table 3). The response ratio varied about zero (which is when variance in gonad development
Table 1. Patella vulgata. ANOVA of 3 replicate measures of aggregation of limpets by Pielou's (1969) $\mathrm{I}_{\alpha}$ at 2 sites on 2 shores (Wembury and Heybrook) on 3 occasions: early September, late October and late December 2003. There was no test for shore. Variances were homogenous after $\ln (x+1)$ transformation $=0.0385, \mathrm{p}>0.05)$; significant terms are in bold; ns: $\mathrm{p}>0.05$; Da: date; Sh: shore; Si: site; Qu: quadrat

Table 2. Patella vulgata. ANOVA of sex ratio for limpets in groups and solitary hores. The data were arcsin-transformed for proportions. Sex ratio was the (impets for which sex could be accurately determined (Orton et al. 1956). Variances were homogenous (sex ratio Cochran's test: $C=0.0675$

Table 1 for other abbreviations

\begin{tabular}{|c|c|c|c|c|c|}
\hline Source & df & MS & $F$ & $\mathrm{p}$ & $F$ versus \\
\hline Da & 7 & 1540.10 & 9.94 & $<0.001$ & $\mathrm{Da} \times \mathrm{Sh}$ \\
\hline $\mathrm{Sh}$ & 1 & 7092.67 & 17.62 & ns & $\mathrm{Si}(\mathrm{Sh})$ \\
\hline $\mathrm{Si}(\mathrm{Sh})$ & 2 & 402.58 & 1.18 & ns & Residual \\
\hline $\mathrm{Ag}$ & 1 & 2326.92 & 3.42 & ns & $\mathrm{Sh} \times \mathrm{Ag}$ \\
\hline $\mathrm{Da} \times \mathrm{Sh}$ & 7 & 154.89 & 0.60 & ns & $\mathrm{Da} \times \mathrm{Si}(\mathrm{Sh})$ \\
\hline $\mathrm{Da} \times \mathrm{Si}(\mathrm{Sh})$ & 14 & 259.15 & 0.76 & ns & Residual \\
\hline $\mathrm{Da} \times \mathrm{Ag}$ & 7 & 245.97 & 1.19 & ns & $\mathrm{Da} \times \mathrm{Sh} \times \mathrm{Ag}$ \\
\hline $\mathrm{Sh} \times \mathrm{Ag}$ & 1 & 679.49 & 2.82 & ns & $\mathrm{Ag} \times \mathrm{Si}(\mathrm{Sh})$ \\
\hline $\mathrm{Ag} \times \mathrm{Si}(\mathrm{Sh})$ & 2 & 241.32 & 0.71 & ns & Residual \\
\hline $\mathrm{Da} \times \mathrm{Sh} \times \mathrm{Ag}$ & 7 & 206.56 & 0.66 & ns & $\mathrm{Ag} \times \mathrm{Da} \times \mathrm{Si}(\mathrm{Sh})$ \\
\hline $\mathrm{Ag} \times \mathrm{Da} \times \mathrm{Si}(\mathrm{Sh})$ & 14 & 314.48 & 0.92 & ns & Residual \\
\hline Residual & 256 & 341.18 & & & \\
\hline Total & 319 & & & & \\
\hline
\end{tabular}

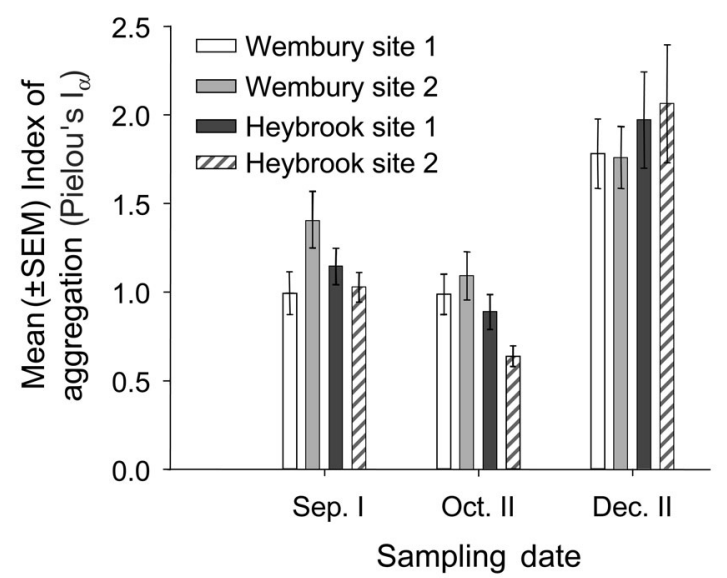

Fig. 1. Patella vulgata. Aggregation of limpets over the sample period. $\mathrm{I}$ = first sampling date, $\mathrm{II}=$ second sampling date in each respective month. Three replicate measures of an index of aggregation (Pielou's $\mathrm{I}_{\alpha}$ ) measured in 10 quadrats at 2 sites on 2 shores at 3 dates; variation in quadrats is indicated by error. Error bars are $\pm \mathrm{SE}$ 


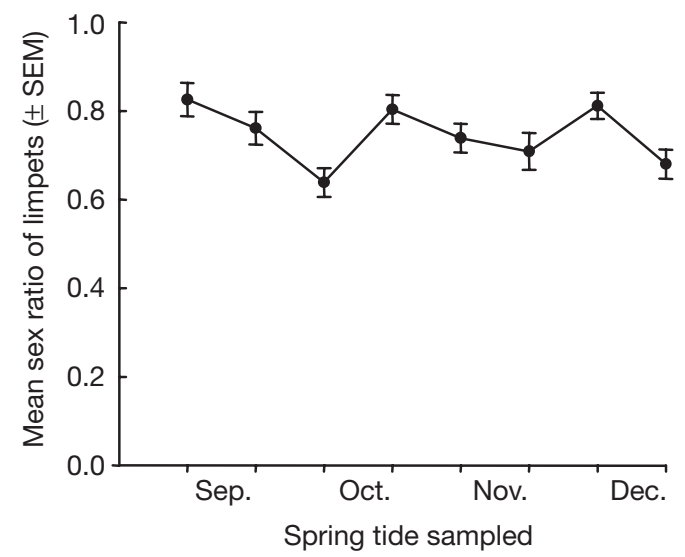

Fig. 2. Patella vulgata. Sex ratio of limpets sampled over the experiment. There were 2 sampling occasions for each month shown. For animals which showed discernible gonad development, we scored the proportion of the group which were female; 1 represents all male animals. Error bars are $\pm \mathrm{SE}$

within groups is equal to the variance in gonad development between solitary limpets in the same site at the same time) (Fig. 4) but was not significantly different from a mean of zero $(t=0.3,179 \mathrm{df}=$ $179, \mathrm{~ns})$.

\section{DISCUSSION}

A fundamental assumption of many explanations of animal aggregation behaviour is that a benefit must exist which exceeds (1) the potential costs of increased apparency to predators and (2) intraspecific competi-

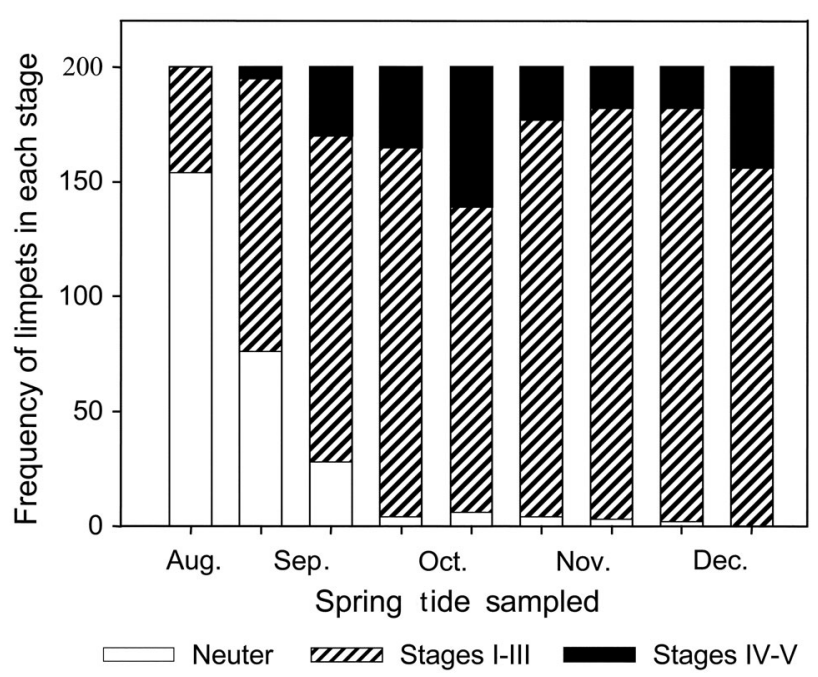

Fig. 3. Patella vulgata. Differences in limpet gonad stage (Orton et al. 1956) across the sampling period. There were 2 sampling occasions for each month except August. To reduce the cell zeros in the analysis, we allocated Stages I-III to one group and Stages IV-V to another
Table 3. Patella vulgata. Synchronicity in gonad development. ANOVA of response ratio of $\ln$ differences in variances within grouped limpets and between solitary limpets. Response ratio variances were homogenous, Cochran's test: $C=0.1066$ (ns); ns: $\mathrm{p}>0.05$; see Table 1 for abbreviations

\begin{tabular}{|lrcccc|}
\hline Source & df & MS & $F$ & $p$ & $F$ versus \\
\hline $\mathrm{Da}$ & 8 & 0.45 & 1.93 & 0.0597 & Residual \\
$\mathrm{Sh}$ & 1 & 0.11 & 2.79 & 0.2371 & Si(Sh) \\
$\mathrm{Si}(\mathrm{Sh})$ & 2 & 0.04 & 0.18 & 0.8386 & Residual \\
$\mathrm{Da} \times \mathrm{Sh}^{\mathrm{a}}$ & 8 & 0.21 & & & \\
$\mathrm{Da} \times \mathrm{Si}(\mathrm{Sh})^{\mathrm{a}}$ & 16 & 0.12 & & & \\
Residual & 144 & 0.23 & & & \\
Total & 179 & & & \\
aFactors eliminated from the analysis as p $>0.25$ (Under- \\
wood 1997)
\end{tabular}

tion causing localised depletion of resources (Krause \& Ruxton 2002). For marine animals forming medium- to long-term aggregations, a major benefit could be elevated reproductive success, and we used mensurative experiments (sensu Hurlbert 1984) to test this idea. We predicted that aggregation should increase nearer the time of spawning, that the sex ratio in groups would be less male biased than between solitary animals and that variation in gonad stage would be less in grouped limpets than in solitary limpets.

Aggregation by limpets did increase from the start of the experiment to the end. Given that removal of limpets did not affect patterns of aggregation, we can offer no explanation for the noted slight reduction in aggregation mid-way through the experimental period. The large increase in aggregation towards

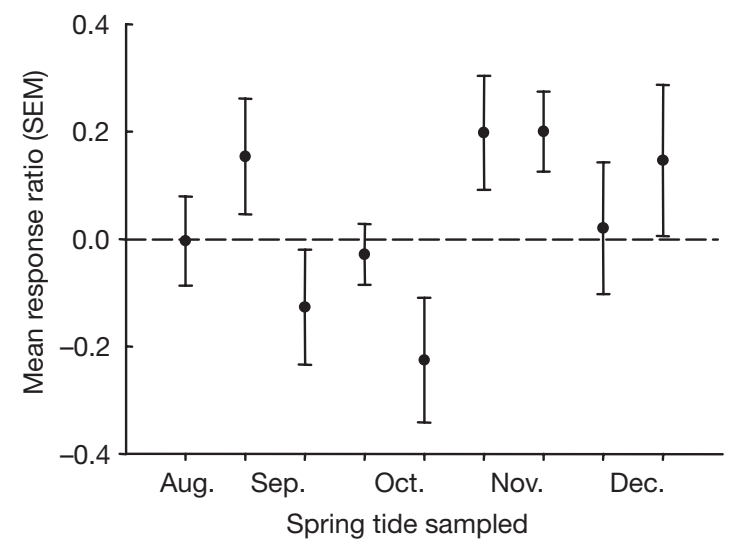

Fig. 4. Patella vulgata. Variation in gonad state within randomly selected solitary limpets and within aggregations of limpets. Patterns of gonad development were examined using variance in gonad stage. The response ratio (Osenberg et al. $1999)$ was defined as $\ln \left(\sigma^{2}\right.$ grouped $)-\ln \left(\sigma^{2}\right.$ solitary) such that when the response ratio is $<0$, groups are more synchronous in gonad development than solitary limpets. There were 2 sampling occasions for each month except August. Error bars are $\pm \mathrm{SE}$ 
mid-winter is consistent with previous observations on Patella vulgata (Coleman et al. 1999). The analysis showed much small-scale spatial variation within this date sequence, which agrees with aggregation studies on other limpets (Coleman et al. 2004b) and littorinids (Chapman 1995). It is highly likely that, as limpets graze and remove microalgae/biofilms, small-scale variations in abundance of food (Jenkins et al. 2001, Jenkins \& Hartnoll 2001) may be influencing patterns of aggregation. This suggestion has yet to be tested.

The prediction of increased reproductive benefit for limpets in groups is not supported by our results. There were no aggregation effects in sex ratio, which, whilst varying from date to date, was overall constant at 3:4 males to females. This differs slightly from the 1:3:1 neuter:male:female ratio reported by Blackmore (1969) for a population of Patella vulgata in north Yorkshire, but the difference may be due to Blackmore's inclusion of limpets as small as $15 \mathrm{~mm}$ length, which often do not exhibit gonad maturation. More males than females in a population mean more sperm. This reduces sperm limitation as a consequence of sperm dilution in seawater, the most important factor in reducing fertilisation success in broadcast spawning invertebrates (Levitan 2002, Metaxas et al. 2002). The average gonad stage was not different for aggregated and solitary limpets at any spatial scale or time during the study. The log-linear analysis showed spatial variation changing with date. This is consistent with small-scale variations in food supply noted elsewhere and on the same shores (Jenkins et al. 2001). The production of gametes is energetically costly and it would not be unreasonable to expect a strong correlation between food abundance and reproductive development, although this has not been tested in limpets. If a reproductive benefit were to exist for aggregated $P$. vulgata, then grouped animals would be expected to be more synchronous in gonad stage and spawning than solitary animals. Therefore, it would be expected that variance in gonad stage would be less in grouped than in solitary limpets, and that these differences should increase as the individuals approach spawning. Whilst there was variation in the response ratio measured, this was not explained by date or spatial considerations. Since the overall response ratio was not different from zero, we can conclude that variance in gonad stage is equal in grouped and solitary limpets. It is clear that in terms of gonad development through to spawning, the evidence does not support the model that limpet aggregation has a reproductive benefit. It is possible that the hydrodynamics over grouped limpets may increase gamete mixing through localised turbulence and so elevate reproductive success for grouped limpet, although data on Patella gamete longevity and fertilisation kinetics are not available. Experiments to test this idea are complex, given the difficulty of fertilisation studies in limpets (A. Hodgson pers. comm.); such data are unlikely to become available in the near future.

Limpets are a key component of rocky shore systems (Hawkins et al. 1992, Underwood 2000, BenedettiCecchi et al. 2001), in that if limpets are removed, rocky shore systems quickly become macroalgal-dominated (Hawkins et al. 1992). Aggregation of limpets may have consequences for spatial patterns of algal escapes (Johnson et al. 1997) if aggregations of limpets translate into aggregated feeding patterns (but see Coleman et al. 2004b); hence, the causes of aggregation behaviour in limpets need to be explained. The increase in limpet aggregation noted in winter may be related to reducing the effect of wave-borne objects (Shanks \& Wright 1986). However, the patterns of aggregation of limpets on smooth rocks do not appear to differ from moderately exposed shores to more exposed shores (R. A. Coleman \& S. King unpubl. data) with their associated differences in risk from waveborne materials; hence, aggregation as a mitigating behaviour to reduce damage from wave-borne objects is probably unlikely. In the northeast Atlantic, predation of limpets by oystercatchers Haematopus ostralegus is highest in the winter, and these predators are much less successful on grouped limpets than on solitary animals (Coleman et al. 1999, 2004a). Since limpet grazing activity decreases in the winter (Jenkins et al. 2001), the expected local depletion of microalgae as a function of grazing activity at the scale of the aggregation may not exceed the benefit from reduced predation risk. Experiments on limpet behavioural responses to changed predation pressure are needed to confirm this model, but it seems likely that the aggregation patterns of this key grazer are best explained not by reproductive gains but by seasonal variations in predation risk balanced against energy intake.

Acknowledgements. This work was partly funded by a Small Project Grant from the British Ecological Society to R.A.C. The authors thank L. Langaard, E. Sheehan and D. Yates for assistance in the field/laboratory, and A. J. Underwood, P. Cotton and R. Thompson for critical advice.

\section{LITERATURE CITED}

Anderson D (1994) Barnacles: structure, function, development and evolution. Chapman \& Hall, London

Ballantine WJ (1961) The population dynamics of Patella vulgata and other limpets. PhD thesis, University of London

Benedetti-Cecchi L, Bulleri F, Acunto S, Cinelli F (2001) Scales of variation in the effects of limpets on rocky shores in the northwest Mediterranean. Mar Ecol Prog Ser 209: 131-141

Blackmore DT (1969) Studies of Patella vulgata L. I. Growth, reproduction and zonal distribution. J Exp Mar Biol Ecol 3: 203-213 
Boaventura D, da Fonseca LC, Hawkins SJ (2002) Analysis of competitive interactions between the limpets Patella depressa Pennant and Patella vulgata L. on the northern coast of Portugal. J Exp Mar Biol Ecol 271:171-188

Branch GM (1985) Limpets: their role in littoral and sub-littoral community dynamics. In: Moore PG, Seed R (eds) The ecology of rocky coasts. Hodder \& Stoughton, London, p 97-116

Chapman MG (1995) Aggregation of the littorinid snail Littorina unifasciata in New South Wales, Australia. Mar Ecol Prog Ser 126:191-202

Coleman RA, Hawkins SJ (2000) Limpet relocation from home-scars in relation to position in a group. J Mar Biol Assoc UK 80:1133-1134

Coleman RA, Goss-Custard JD, LeV. dit Durell SEA, Hawkins SJ (1999) Limpet Patella spp. consumption by oystercatchers Haematopus ostralegus: a preference for solitary prey items. Mar Ecol Prog Ser 183:253-261

Coleman RA, Browne M, Theobalds T (2004a) Prey aggregation functioning as a group defense via vibration-vigilance: limpet tenacity changes in response to simulated predator attack. Ecology 85:1153-1159

Coleman RA, Underwood AJ, Chapman MG (2004b) Absence of costs of foraging excursions in relation to limpet aggregation. J Anim Ecol 73:577-584

Denny MW, Shibata MF (1989) Consequences of surf-zone turbulence for settlement and external fertilisation. Am Nat 134:859-889

Dunmore RA, Schiel DR (2003) Demography, competitive interactions and grazing effects of intertidal limpets in southern New Zealand. J Exp Mar Biol Ecol 288:17-38

Feare CJ (1971) The adaptive significance of aggregation behaviour in the dogwhelk Nucella lapillus. Oecologia 7: $117-126$

Hamilton WD (1971) Geometry for the selfish herd. J Theor Biol 31:295-311

Hartnoll RG, Hawkins SJ (1985) Patchiness and fluctuations on moderately exposed rocky shores. Ophelia 24:53-63

Hawkins SJ (1981) The influence of season and barnacles on the algal colonisation of Patella vulgata exclusion areas. J Mar Biol Assoc UK 61:1-15

Hawkins SJ, Hartnoll RG (1983) Grazing of intertidal algae by marine invertebrates. Oceanogr Mar Biol Annu Rev 21: 195-282

Hawkins SJ, Hartnoll RG, Kain JM, Norton TA (1992) Plantanimal interactions on hard substrata in the North-East Atlantic. In: John DM, Hawkins SJ, Price JH (eds) Plantanimal interactions in the marine benthos. Systematics Assoc Spec Vol No. 46, Clarendon Press, Oxford, p 1-32

Hedges LV, Gurevitch J, Curtis PS (1999) The meta-analysis of response ratios in experimental ecology. Ecology 80: $1150-1156$

Hurlbert SH (1984) Pseudoreplication and the design of ecological field experiments. Ecol Monogr 54:187-221

Jenkins SR, Hartnoll RG (2001) Food supply, grazing activity and growth rate in the limpet Patella vulgata L.: a comparison between exposed and sheltered shores. J Exp Mar Biol Ecol 258:123-139

Jenkins SR, Arenas F, Arrontes J, Bussell J and 10 others (2001) A European-scale analysis of seasonal variability in limpet grazing activity and microalgal abundance. Mar Ecol Prog Ser 211:193-203

Johnson MP, Burrows MT, Hartnoll RG, Hawkins SJ (1997) Spatial structure on moderately exposed rocky shores: patch scales and the interaction between limpets and algae. Mar Ecol Prog Ser 160:209-215

Jones NS (1946) The browsing of Patella. Nature 158:557

Editorial responsibility: Otto Kinne (Editor-in-Chief),

Oldendorf/Luhe, Germany
Jones NS (1948) Observations and experiments on the biology of Patella vulgata at Port St. Mary, Isle of Man. Proc Trans Liverpool Biol Soc 56:60-77

Kent A, Hawkins SJ, Doncaster CP (2003) Population consequences of mutual attraction between settling and adult barnacles. J Anim Ecol 72:941-952

Kenward RE (1978) Hawks and doves: factors affecting success and selection in goshawk attacks on wood pigeons. J Anim Ecol 47:449-460

Krause J, Ruxton GD (2002) Living in groups. Oxford University Press, Oxford

Levitan DR (1996) Effects of gamete traits on fertilisation in the sea and the evolution of sexual dimorphism. Nature 382:153-155

Levitan DR (2002) Density-dependent selection on gamete traits in three congeneric sea urchins. Ecology 83:464-479

Levitan DR, Petersen C (1995) The ecology of fertilisation in free-spawning invertebrates. In: McEdward L (ed) Ecology of marine invertebrate larvae. CRC Press, Boca Raton, FL, p 123-156

Levitan DR, Sewell MA, Chia FS (1991) Kinetics of fertilisation in the sea-urchin Strongylocentrotus franciscanus: interaction of gamete dilution, age, and contact time. Biol Bull 181:261-268

Lewis JR, Bowman RS (1975) Local habitat induced variations in population dynamics of Patella vulgata L. J Exp Mar Biol Ecol 104:185-201

Metaxas A, Scheibling RE, Young CM (2002) Estimating fertilisation success in marine benthic invertebrates: a case study with the tropical sea star Oreaster reticulatus. Mar Ecol Prog Ser 226:87-101

Orton JH, Southward AJ, Dodd JM (1956) Studies on the biology of limpets II. The breeding of Patella vulgata L. in Britain. J Mar Biol Assoc UK 35:149-176

Osenberg CW, Sarnelle O, Cooper SD, Holt RD (1999) Resolving ecological questions through meta-analysis: goals, metrics, and models. Ecology 80:1105-1117

Parrish JK, Edelstein-Keshet L (1999) Complexity, pattern, and evolutionary trade-offs in animal aggregation. Science 284:99-101

Pennington JT (1985) The ecology of fertilisation of echinoid eggs - the consequences of sperm dilution, adult aggregation, and synchronous spawning. Biol Bull 169:417

Pielou EC (1969) An introduction to mathematical ecology. Wiley-Interscience, New York

Powell DK, Tyler PA, Peck LS (2001) Effect of sperm concentration and sperm ageing on fertilisation success in the Antarctic soft-shelled clam Laternula elliptica and the Antarctic limpet Nacella concinna. Mar Ecol Prog Ser 215: 191-200

Shanks AL, Wright WG (1986) Adding teeth to wave action: the destructive effects of wave-borne rocks on intertidal organisms. Oecologia 69:420-428

Sokal RR, Rohlf FJ (1995) Biometry. WH Freeman, New York

Southward AJ, Southward EC (1978) Recolonisation of rocky shores in Cornwall after the use of toxic dispersants to clean up the Torrey Canyon oil spill. J Fish Res Board Can 35:682-706

Thompson GB (1980) Distribution and population dynamics of the limpet Patella vulgata L. in Bantry Bay. J Exp Mar Biol Ecol 45:173-217

Underwood AJ (1997) Experiments in ecology: their logical design and interpretation using analysis of variance. Cambridge University Press, Cambridge

Underwood AJ (2000) Experimental ecology of rocky intertidal habitats: What are we learning? J Exp Mar Biol Ecol 250:51-76

Submitted: March 14, 2005; Accepted: July 17, 2005

Proofs received from author(s): December 6, 2005 